\title{
PENGUJIAN STRUKTUR BOM LATIH GUNA MENGETAHUI FREKUENSI PRIBADI DAN BEBAN DINAMIS
}

\author{
Erna Kusuma Wati ${ }^{1 *}$, Sri Wahyuni Sitorus ${ }^{2}$ \\ Program Studi Teknik Fisika, Universitas Nasional ${ }^{1,2}$ \\ ernakusuma.w@gmail.com
}

Submitted August 13, 2021; Revised December 4, 2021; Accepted December 4, 2021

\begin{abstract}
Abstrak
Untuk menjaga keamanan pilot dalam membawa pesawat pengangkut bom, maka diperlukan beberapa persyaratan uji struktur bagi seluruh komponen bom latih. Pengujian struktur bom latih meliputi : pengukuran frekuensi pribadi bom latih dengan cara uji getar, pengujian dengan beban dinamis dan beban kejut serta uji statik pada struktur benda uji bom latih. Pada penelitian ini akan melakukan semua pengujian tersebut. Penelitian ini dilaksanakan di laboratorium Balai Besar Teknologi Kekuatan Struktur (B2TKS-BPPT). Hasil pengujian menunjukkan bahwa struktur bom latih ${ }^{1}$ mempunyai frekuensi pribadi di atas $33 \mathrm{hz}$. Struktur bom latih mempunyai ketahanan terhadap beban dinamis $2 \mathrm{~g}$ dan beban kejut $10 \mathrm{~g}$ serta $16 \mathrm{~g}$ tanpa terjadi kerusakan. Kekuatan tarik suspension lug dengan kondisi terpasang 4 ulir dari benda uji bom latih yang sudah mengalami vibrasi dan beban kejut 6 jam adalah $47.5 \mathrm{kn}(21.5 \mathrm{~g})$. Sedangkan kekuatan tarik suspension lug dengan kondisi terpasang full ulir adalah $52.5 \mathrm{kn}(23 \mathrm{~g})$. Kekuatan tarik suspension lug dengan kondisi terpasang 4 ulir dari benda uji bom latih ${ }^{2}$ yang tidak pernah mengalami vibrasi dan beban kejut adalah $82.5 \mathrm{kn}(38 \mathrm{~g})$, sedangkan kekuatan tarik suspension lug dengan kondisi terpasang full ulir adalah $77.5 \mathrm{kn}(36 \mathrm{~g})$.
\end{abstract}

Kata Kunci : Bom Latih, Uji Struktur, Vibrasi, Frekuensi Pribadi

\begin{abstract}
To maintain the safety of pilots in carrying bomb-carrying aircraft, several structural test requirements are needed for all training bomb components. Testing the structure of the training bomb includes: measuring the personal frequency of the training bomb by means of a vibration test, testing with dynamic loads and shock loads and static tests on the structure of the training bomb test object. In this study, all these tests will be carried out. This research was carried out in the laboratory of Balai Besar Teknologi Kekuatan Struktur (B2TKS-BPPT). The test results show that the training bomb ${ }^{l}$ structure has a personal frequency above $33 \mathrm{~Hz}$. The training bomb structure has resistance to dynamic loads of $2 \mathrm{~g}$ and shock loads of $10 \mathrm{~g}$ and $16 \mathrm{~g}$ without any damage. The tensile strength of the suspension lug with 4 threads installed from the drill bomb test object which has been subjected to vibration and shock load for 6 hours is $47.5 \mathrm{kn}(21.5 \mathrm{~g})$. While the tensile strength of the suspension lug with fully threaded conditions is $52.5 \mathrm{kn}(23 \mathrm{~g})$. The tensile strength of the suspension lug with 4 threads installed from the drill bomb test ${ }^{2}$ object which has never experienced vibration and shock loads is $82.5 \mathrm{kn}(38 \mathrm{~g})$. while the tensile strength of the suspension lug with fully screwed conditions is $77.5 \mathrm{kn}(36 \mathrm{~g})$.
\end{abstract}

Key Words : Training Bomb, Structural Test, Vibration, Personal Frequency

\section{PENDAHULUAN}

Pesawat tempur yang terlibat membawa aneka jenis persenjataan udara ke udara dan udara kedarat, termasuk bom yang tergantung di bawah body maupun sayap pesawat sebelum diterbangkan harus melakukan pengecekan secara 
keseluruhan, termasuk pengecekan bom yang dibawa [1]. Dalam bidang penerbangan, keamanan penumpang dan kru menjadi prioritas utama. Karena jika terjadi kesalahan, maka keselamatan akan sangat terancam [1]. Pengujian ini dimaksudkan untuk memastikan apakah bom latih benar-benar aman dalam kondisi terbang sebenarnya [2]. Bom latih adalah bom yang digunakan dalam latihan pesawat tempur, yang mana bom memiliki struktur yang sama dengan bom asli, hanya saja tidak memiliki bahan peledak di dalamnya. Pengujian struktur bom latih meliputi :

1. Pengukuran frekuensi pribadi bom latih melalui pengukuran vibrasi (getaran),

2. Pengujian dengan beban dinamis dan beban kejut

3. Uji statik pada struktur benda uji Bom Latih.

Frekuensi pribadi (Natural Frequency) adalah frekuensi dari sistem getaran bebas (free vibration) tanpa peredaman yang ditentukan oleh sifat dari sistem tersebut. Pengukuran frekuensi pribadi bom latih bertujuan untuk mengetahui apakah bom latih memiliki frekuensi pribadi yang sama dengan pesawat. Pesawat tempur pada umumnya memiliki frekuensi pribadi sekitar 5 s/d $15 \mathrm{~Hz}$. Jika berada pada rentang yang sama maka akan terjadi resonansi [3]. Resonansi adalah Peningkatan frekuensi pribadi suatu sistem menyebabkan terjadinya getaran yang sangat besar. Getaran tersebut mengakibatkan terjadinya kerusakan pada suatu bagian tertentu [4] dari sistem tersebut. Jika resonansi terjadi maka, bom dapat meledak ketika terbang. Untuk mengukur vibrasi (getaran) alat yang digunakan adalah accelerometer. Prinsip kerja sensor accelerometer adalah prinsip kerja percepatan. Accelerometer mampu mengukur percepatan linier dalam tiga sumbu ( $\mathrm{x}, \mathrm{y}$ dan $\mathrm{z}$ ) [5]. Geraknya benda bermassa pada accelerometer yang diakibatkan oleh adanya gaya, sesuai dengan hukum kedua newton.

\section{METODE PENELITIAN}

\section{Data Benda Uji}

Benda uji terdiri dari 2 set bom dengan empat buah suspension lug. Bom ini container-nya terbuat dari material baja. Struktur Bom Latih terdiri dari beberapa komponen antara lain badan bom, ekor assy dan suslug. Berat bom adalah Bom $\operatorname{Latih}(1)=2,21 \mathrm{kN}$ dan $\operatorname{Bom} \operatorname{Latih}(2)=$ $2,14 \mathrm{kN}$.

Tabel 1. Jenis Pengujian Pada Dua Benda Uji

\begin{tabular}{ccl}
\hline No & Benda Uji & \multicolumn{1}{c}{ Jenis Pengujian } \\
\hline & & $\begin{array}{l}\text { Uji vibrasi dan uji dengan beban } \\
\text { dinamis/kejut }\end{array}$ \\
1 & Bom Latih (1) & $\begin{array}{l}\text { Uji dengan beban statis (4 ulir } \\
\text { terpasang) } \\
\text { Uji dengan beban statis (full ulir } \\
\text { terpasang) }\end{array}$ \\
\hline 2 & Bom Latih & $\begin{array}{l}\text { Uji dengan beban statis (4 ulir } \\
\text { terpasang) } \\
\text { Uji dengan beban statis (full ulir } \\
\text { terpasang) }\end{array}$ \\
\hline
\end{tabular}

Spesifikasi teknik bom latih terdiri dari :

1. Kaliber $: 250 \mathrm{~kg}$

2. Panjang Total $: 1500 \mathrm{~mm}$

3. Panjang body $: 845 \mathrm{~mm}$

4. Diameter body : $350 \mathrm{~mm}$

5. Bahan Body : Baja SC 37-46

6. Letak CG : $498.98 \mathrm{~mm}$

7. Bahan Peledak :-

8. Panjang Tail Bomb: $655 \mathrm{~mm}$

9. Fin span : $350 \mathrm{~mm}$

10. Bahan Fin : Baja ST-37

11. Jumlah Suslug : 2 (dua) buah

12. Jarak antara Suslug: $250 \mathrm{~mm}$

13. Bahan Suslug : Baja VCN 45

14. Jenis fuze : AVU-ETM/AVE - ETME

15. Jenis Cat Bom : Army green dop No. 3303 dan Atau setara 


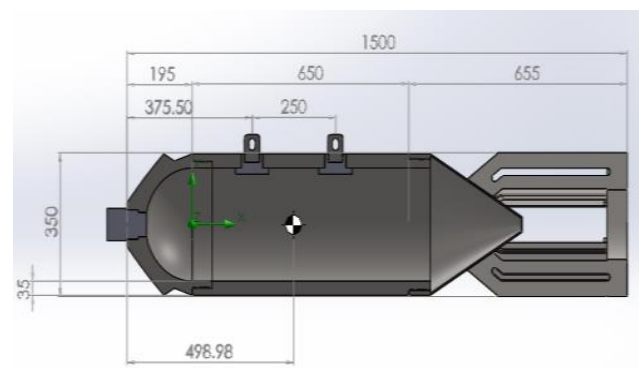

Gambar 1. Bentuk dan susunan struktur benda uji Bom Latih

Peralatan yang digunakan untuk pengujian struktur bom latih adalah :

1. Jig dan rig (1 set)

2. Servocontroller, Kelsey Instrument (1 set)

3. PC dan Dynamic Loading Program (1 set)

4. Mesin servohydraulic, Kapasitas 250 $\mathrm{kN}$ (1 set)

5. Accelerometer, Type B 12/200, kapasitas $40 \mathrm{~g}$ (1 set)

6. Spectrum Analyzer, ONO SOKKI 2 channels (1 set) Peralatan Inspeksi (MPI)

\section{Metode Pengujian}

\section{Pengukuran getaran untuk mengetahui frekuensi pribadi}

Pengukuran frekuensi pribadi [6] dilakukan dengan cara mengukur respon benda uji dengan memberikan eksitasi getaran [7] berbentuk sinusiodal dengan amplitudo konstan sebesar $\pm 0.5 \mathrm{~mm}$ dan frekuensi berubah dari 0 s/d $33 \mathrm{~Hz}$ (kemampuan rig dan mesin uji s/d $33 \mathrm{~Hz}$ ). Frekuensi pribadi akan dapat diketahui [8] jika terjadi resonansi pada benda uji. Resonansi tersebut akan ditunjukkan oleh terjadinya kenaikan amplitudo getaran dan setelah frekuensi pribadi terlampaui maka amplitudo getaran akan menurun kembali. Pengamatan mode getaran dilakukan dengan menggunakan accelerometer sebagai sensor percepatan dan dianalisis dengan menggunakan spectrum analyzer kemudian hasilnya diprint yang berupa grafik percepatan getaran vs frekuensi.

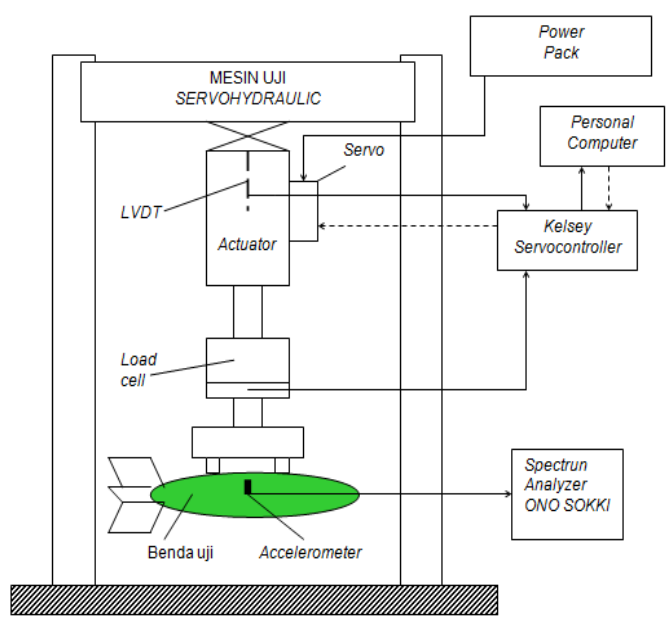

Gambar 2. Set-up dan Sistem Pengukuran Getaran dan Uji Dinamis / Kejut

Pengujian Dinamis untuk Mengetahui Kekuatan Sistem Gantungan dan Struktur Bom Akibat Beban Dinamis dan Kejut

Pengujian dinamis dengan beban dinamis dan beban kejut yang dimaksudkan yaitu apabila benda uji dibebani dengan beban dinamis berulang (beban berubah terhadap waktu) dan suatu saat atau periode tertentu diberikan sebuah amplitudo yang relatif lebih tinggi dari yang lain (over load). Untuk pengujian ini beban yang diberikan pada Bom Latih (1) adalah sinusoidal dengan amplitudo konstan dilakukan berulang dengan besar beban, frekuensi dan waktu pengujian tertentu. Waktu pengujian setiap benda uji adalah 6 jam dan setiap interval 10 menit diberikan beban kejut. Pada 3 jam pertama beban dinamis yang diberikan yaitu Fmax $=5 \mathrm{kN}$ $(2 \mathrm{~g})$, Fmin $=0,25 \mathrm{kN}$ dan beban kejut (overload) sebesar $25 \quad \mathrm{kN} \quad$ (10g). Sedangkan pada 3 jam kedua besar beban dinamis yang diberikan yaitu Fmax $=5 \mathrm{kN}$ $(2 \mathrm{~g})$, Fmin $=0,25 \mathrm{kN}$ dan beban kejut sebesar $40 \mathrm{kN}$ (16g). Frekuensi pengujian sebesar $8 \mathrm{~Hz}$. Pemeriksaan NDT dilakukan sebelum dan sesudah pengujian. (catatan: Menggunakan swaybrace dengan jarak gantungan $250 \mathrm{~mm}$. Skema set-up dan 
sistem pengujian seperti ditunjukkan pada Gambar 2.2.

\section{Pengujian Statik}

Pengujian statik pada Bom Latih (2) dilakukan langsung setelah dilakukan basic inspection, sedangkan pengujian statik pada Bom Latih (1) dilakukan setelah pengujian vibrasi dan beban kejut selama 6 jam.Pengujian statik pada Bom Latih dilakukan dengan menahan container dari bom (di-clamp ke strong floor) kemudian menarik suspension lug (posisi 4 ulir dan full ulir terpasang ) dengan aktuator 250 $\mathrm{kN}$. Selama pengujian, grafik hubungan gaya dan langkah mesin (stroke) direkam dengan $X-Y$ Recorder. Skema set-up dan sistem pengujian seperti ditunjukkan pada Gambar 3.

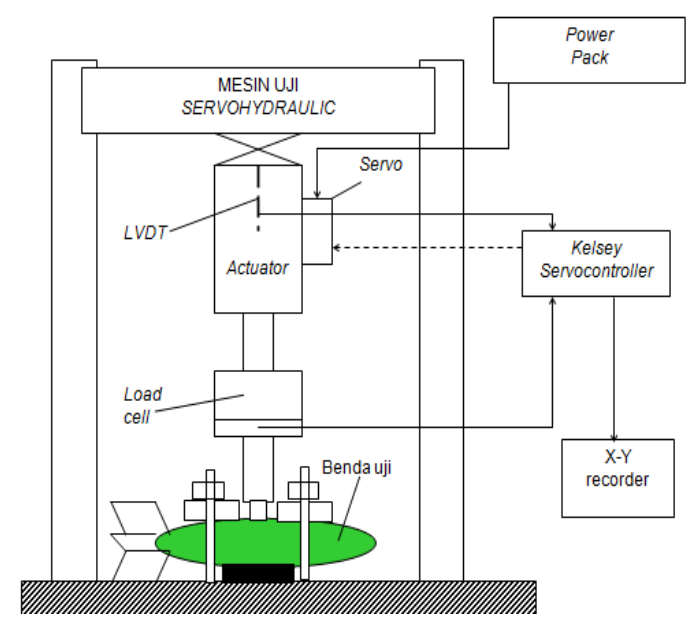

\section{Gambar 3. Set-up dan Sistem Uji Statik}

\section{HASIL DAN PEMBAHASAN}

\section{Hasil Pegujian Frekuensi Pribadi}

Dari hasil pengukuran yang terdapat dalam Tabel 2 terlihat bahwa frekuensi pribadi dari bom belum ditemukan sampai pengujian getar dengan frekuensi $33 \mathrm{~Hz}$ (kecenderungannya masih naik). Karena itu jika frekuensi pribadi sayap pesawat pengangkutnya sekitar $5 \mathrm{~s} / \mathrm{d} 15 \mathrm{~Hz}$ (pada umumnya) maka dalam penggunaannya tidak akan terjadi resonansi antara bom dan sayap pesawat pengangkutnya (masih aman).
Tabel 2. Hasil Pengukuran Getaran Struktur Bom Latih (1) (Frekuensi Actuator Berubah dari 0 s/d 33 Hz)

\begin{tabular}{|c|c|c|c|c|}
\hline \multirow{3}{*}{$\begin{array}{l}\text { Frekuensi } \\
\qquad(\mathrm{Hz})\end{array}$} & \multicolumn{4}{|c|}{ Besarnya Akselerasi (m/s2) } \\
\hline & \multicolumn{3}{|c|}{ Badan } & Ekor \\
\hline & Vertikal & Longitudinal & Lateral & Vertikal \\
\hline 1 & 0.006 & 0.065 & 0.003 & 0.0001 \\
\hline 2 & 0.247 & 0.205 & 0.003 & 0.027 \\
\hline 3 & 0.082 & 0.068 & 1.719 & 1.104 \\
\hline 4 & 0.151 & 0.053 & 0.283 & 0.149 \\
\hline 5 & 0.244 & 0.039 & 0.011 & 0.288 \\
\hline 6 & 0.35 & 0.056 & 0.513 & 0.375 \\
\hline 7 & 0.469 & 0.018 & 0.022 & 0.496 \\
\hline 8 & 0.606 & 0.059 & 0.038 & 0.646 \\
\hline 9 & 0.805 & 0.033 & 0.279 & 0.806 \\
\hline 10 & 1.009 & 0.039 & 0.138 & 1.040 \\
\hline 11 & 1.222 & 0.064 & 0.154 & 1.250 \\
\hline 12 & 1.466 & 0.052 & 0.988 & 1.487 \\
\hline 13 & 1.733 & 0.049 & 1.356 & 1.769 \\
\hline 14 & 2.015 & 0.081 & 0.669 & 2.087 \\
\hline 15 & 2.319 & 0,089 & 0.530 & 2.366 \\
\hline 16 & 2.665 & 0.075 & 1.144 & 2.750 \\
\hline 17 & 3.300 & 0.125 & 1.023 & 3.135 \\
\hline 18 & 3.186 & 0.111 & 0.746 & 3.490 \\
\hline 19 & 3.736 & 0.108 & 0.044 & 3.966 \\
\hline 20 & 4.211 & 0.126 & 2.107 & 4.471 \\
\hline 21 & 4.641 & 0.147 & 0.121 & 5.101 \\
\hline 22 & 5.155 & 0.223 & 0.110 & 5.776 \\
\hline 23 & 5.638 & 0.073 & 0.103 & 5.797 \\
\hline 24 & 5.984 & 0.108 & 0.464 & 6.673 \\
\hline 25 & 6.846 & 0.132 & 0.231 & 7.475 \\
\hline 26 & 7.057 & 0.157 & 0.482 & 8.160 \\
\hline 27 & 8.181 & 0.151 & 0.188 & 9.495 \\
\hline 28 & 8.974 & 0.168 & 0.248 & 10.028 \\
\hline 29 & 9.713 & 0.186 & 0.266 & 10.806 \\
\hline 30 & 10.575 & 0.124 & 0.287 & 11.227 \\
\hline 31 & 11.244 & 0.136 & 0.308 & 12.866 \\
\hline 32 & 12.303 & 0.126 & 0.324 & 13.477 \\
\hline 33 & 13.041 & 0.090 & 0.309 & 13.824 \\
\hline
\end{tabular}

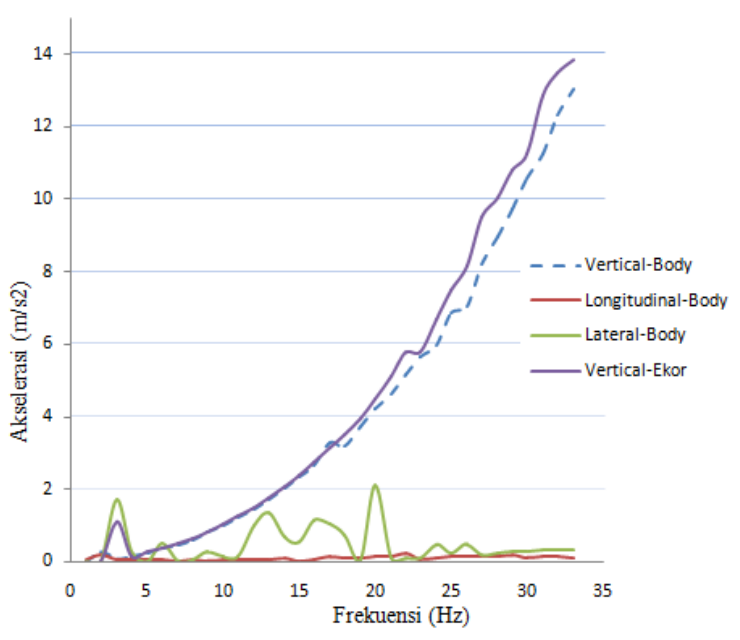

Gambar 4. Grafik Hubungan antara Percepatan dan Frekuensi pada Uji Vibrasi Bom Latih (1) 


\section{Ketahanan Struktur Bom Terhadap Beban Dinamis dan Beban Kejut}

Pengujian dinamis dengan beban kejut 50 $\mathrm{kN}$ (setara $10 \mathrm{~g}$ ) tiap 10 menit dilakukan pada benda uji sampai dengan 86.200 siklus dengan frekuensi $8 \mathrm{~Hz}$ (3 jam pertama). Dari hasil pengujian dinamis terlihat bahwa benda uji tidak mengalami kerusakan hingga 86.200 siklus. Pada persiapan pengujian dinamis dengan beban kejut $80 \mathrm{kN}$ (setara $16 \mathrm{~g}$ ) tiap 10 menitdilakukan pada benda uji sampai dengan 86.200 siklus dengan frekuensi 8 $\mathrm{Hz}$ (3 jam kedua), benda uji tidak mengalami kerusakan. Kondisi struktur bom saat NDT/ basic inspection tidak ada retak.

Tabel 3. Hasil Pengujian Dinamis/ kejut Struktur Bom Latih (1)

\begin{tabular}{|c|c|c|c|c|}
\hline No & $\begin{array}{c}\text { Benda } \\
\text { uji }\end{array}$ & Beban & Siklus & Keterangan \\
\hline \multicolumn{5}{|c|}{ Beban Kejut 10 g ( Lama Waktu Uji 3 jam) } \\
\hline \multirow{3}{*}{1} & \multirow{3}{*}{$\begin{array}{l}\text { Bom } \\
\text { Latih } \\
\text { (1) }\end{array}$} & $\begin{array}{l}\text { Fmax }=5 \mathrm{kN} \\
(2 \mathrm{~g})\end{array}$ & \multirow{3}{*}{86.200} & \multirow{3}{*}{$\begin{array}{l}\text { Benda uji } \\
\text { tidak rusak }\end{array}$} \\
\hline & & $\begin{array}{l}\text { Fmin }=0,25 \\
\mathrm{kN}\end{array}$ & & \\
\hline & & $\begin{array}{l}\text { Overload = } \\
25 \mathrm{kN}(10 \mathrm{~g}) .\end{array}$ & & \\
\hline \multicolumn{5}{|c|}{ Beban Kejut 16 g ( Lama Waktu Uji 3 jam) } \\
\hline \multirow{3}{*}{1} & \multirow{3}{*}{$\begin{array}{l}\text { Bom } \\
\text { Latih } \\
\text { (1) }\end{array}$} & $\begin{array}{l}\text { Fmax }=5 \mathrm{kN} \\
(2 \mathrm{~g})\end{array}$ & \multirow{3}{*}{86.200} & \multirow{3}{*}{$\begin{array}{l}\text { Benda uji } \\
\text { tidak rusak }\end{array}$} \\
\hline & & $\begin{array}{l}\text { Fmin }=0,25 \\
\mathrm{kN}\end{array}$ & & \\
\hline & & $\begin{array}{l}\text { Overload = } \\
40 \mathrm{kN}(16 \mathrm{~g}) .\end{array}$ & & \\
\hline
\end{tabular}

\section{Kekuatan Suspension Lug}

Pengujian statik suspension lug dari bom telah dilakukan dan hasilnya ditampilkan pada Tabel 4 dan grafik pada Gambar berikut :
Tabel 4. Hasil Uji statik Bom Latih

\begin{tabular}{|c|c|c|c|}
\hline No & Benda Uji & $\begin{array}{l}\text { Beban } \\
\text { [ kN ] }\end{array}$ & Keterangan \\
\hline 1 & $\begin{array}{l}\text { Gantungan } \\
\text { depan } \\
(4 \text { ulir })(1)\end{array}$ & 47.5 & $\begin{array}{l}\text { Beban setara } \\
21.5 \mathrm{~g} \text { dan benda } \\
\text { Uji rusak(suslug } \\
\text { patah) }\end{array}$ \\
\hline 2 & $\begin{array}{l}\text { Gantungan } \\
\text { belakang } \\
\text { (full ulir) (1) }\end{array}$ & 52.5 & $\begin{array}{l}\text { Beban setara } 23 \mathrm{~g} \\
\text { dan benda Uji } \\
\text { rusak(suslug } \\
\text { patah) }\end{array}$ \\
\hline 3 & $\begin{array}{l}\text { Gantungan } \\
\text { depan } \\
(4 \text { ulir })(2)\end{array}$ & 81.25 & $\begin{array}{l}\text { Beban setara } 38 \mathrm{~g} \\
\text { dan benda Uji } \\
\text { rusak(suslug } \\
\text { patah) }\end{array}$ \\
\hline 4 & $\begin{array}{l}\text { Gantungan } \\
\text { belakang } \\
\text { (full ulir) (2) }\end{array}$ & 77.5 & $\begin{array}{l}\text { Beban setara } 36 \mathrm{~g} \\
\text { dan benda Uji } \\
\text { rusak (suslug } \\
\text { patah) }\end{array}$ \\
\hline
\end{tabular}
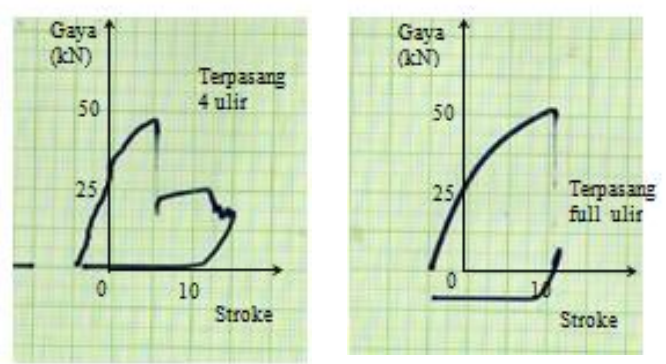

Gambar 5. Grafik hubungan Gaya vs Langkah mesin (stroke) Pada uji statik Bom Latih (1)
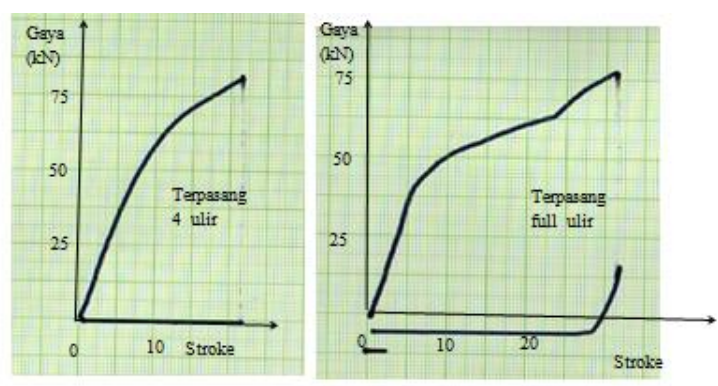

Gambar 6. Grafik hubungan Gaya vs Langkah mesin (stroke) pada uji statik Bom Latih (2) 


\section{SIMPULAN}

Dari hasil pengujian dan pembahasan benda uji Bom Latih di atas, disimpulkan bahwa :

1. Struktur Bom Latih (1) mempunyai frekuensi pribadi di atas $33 \mathrm{~Hz}$.

2. Struktur Bom Latih (1) mempunyai ketahanan terhadap beban dinamis $2 \mathrm{~g}$ dan beban kejut $10 \mathrm{~g}$ serta $16 \mathrm{~g}$ tanpa terjadi kerusakan.

3. Kekuatan tarik suspension lug dengan kondisi terpasang 4 ulir dari benda uji Bom Latih (1) yang sudah mengalami vibrasi dan beban kejut 6 jam adalah $47.5 \mathrm{kN}(21.5 \mathrm{~g})$. Sedangkan kekuatan tarik suspension lug dengan kondisi terpasang full ulir adalah $52.5 \mathrm{kN}$ (23g).

Kekuatan tarik suspension lug dengan kondisi terpasang 4 ulir dari benda uji Bom Latih (2) yang tidak pernah mengalami vibrasi dan bebab kejut adalah $82.5 \mathrm{kN}$ (38g). Sedangkan kekuatan tarik suspension.

\section{DAFTAR PUSTAKA}

[1] Eddy priyono, "reverse engineering high drag bomb," vol. 1, no. 3, pp. 1-8, 2011.

[2] D. Ependi, A. Prasetya, and A. Armawi, "strategi produksi 'bom $p$ 100 live' untuk pemenuhan kebutuhan dalam negeri guna mendukung ketahanan alat utama sistem senjata (studi di pt. Dahana (persero) subang, provinsi jawa barat)," j. Ketahanan nas., vol. 25, no. 1, p. 15, 2019, doi: 10.22146/jkn.42697.
[3] S. S. Rahardi, "Perhitungan Nilai Frekuensi Untuk Uji Getar Produk Aki Berdasarkan SNI 0038: 2009 Frequency Value Calculation For Vibration Test Of Lead Acid," vol. 2009, pp. 37-40, 2009.

[4] M. F. Ikhwansyah Isranuri, "Simulasi Getaran Berbasis Metode Elemen Hingga Menggunakan Software Ansys Untuk Mengidentifikasi Kondisi Komponen Utama Turbin Pembangkit Listrik," no. 2, pp. 2735, 2020.

[5] D. Alfas Zainur Rohman, "Rancang Bangun Alat Ukur Getaran Menggunakan Sensor Micro Electro Mechanical System (Mems) Akselerometer," Edu Elektr. J., vol. 4, no. 1, pp. 8-16, 2015.

[6] Mustafa, "Penentuan Frekuensi Pribadi Pada Getaran Balok," vol. 2, no. 2, pp. 163-168, 2011.

[7] A. Priantoko, A. Murdifin, A. Adkhiyan, and S. Slamet, "Optimasi Desain Struktur Bed Mesin Bubut Cnc Terhadap Pengaruh Defleksi, Frekuensi Pribadi Dan Proses Manufaktur Milling," Simetris J. Tek. Mesin, Elektro dan Ilmu Komput., vol. 7, no. 1, p. 39, 2016, doi: 10.24176/simet.v7i1.486.

[8] A. U. Fajar Aswin, M. Riva'i, Dedy Firmansyah, "Analisis Hasil Rekondisi Mesin Frais Aciera F3 Terhadap," pp. 25-31. 